\title{
Dupuytren's: a systems biology disease
}

\author{
Samrina Rehman', Royston Goodacre ${ }^{2}$, Philip J Day ${ }^{3}$, Ardeshir Bayat ${ }^{4}$ and Hans V Westerhoff',5*
}

\begin{abstract}
Dupuytren's disease (DD) is an ill-defined fibroproliferative disorder of the palm of the hands leading to digital contracture. DD commonly occurs in individuals of northern European extraction. Cellular components and processes associated with DD pathogenesis include altered gene and protein expression of cytokines, growth factors, adhesion molecules, and extracellular matrix components. Histology has shown increased but varying levels of particular types of collagen, myofibroblasts and myoglobin proteins in DD tissue. Free radicals and localised ischaemia have been suggested to trigger the proliferation of DD tissue. Although the existing available biological information on DD may contain potentially valuable (though largely uninterpreted) information, the precise aetiology of DD remains unknown. Systems biology combines mechanistic modelling with quantitative experimentation in studies of networks and better understanding of the interaction of multiple components in disease processes. Adopting systems biology may be the ideal approach for future research in order to improve understanding of complex diseases of multifactorial origin. In this review, we propose that DD is a disease of several networks rather than of a single gene, and show that this accounts for the experimental observations obtained to date from a variety of sources. We outline how DD may be investigated more effectively by employing a systems biology approach that considers the disease network as a whole rather than focusing on any specific single molecule.
\end{abstract}

\section{Introduction}

The quasi-neoplastic nodular palmar fibromatosis [1] called Dupuytren's disease (DD) often causes permanent

*Correspondence: Hans.Westerhoff@manchester.ac.uk: for clinical relevance please contact Ardeshir.bayat@manchester.ac.uk

'Manchester Centre for Integrative Systems Biology, Manchester Interdisciplinary Biocentre, University of Manchester, Manchester, M1 7DN, UK

Full list of author information is available at the end of the article flexion contracture of the metacarpophalangeal and proximal interphalangeal joints of the digits [2,3] (Figure 1), leading to loss of function, deformity of the hand, and permanent contracture of the involved digits $[2,4]$. Although DD does not metastasize [5], it may invade locally within the palmar aponeurosis of the hand (sparingly supplied with blood vessels) and it is progressive with a high rate of recurrence after surgical excision [6], often requiring amputation of the affected digit [7-9]. The three stages of DD growth (proliferative, involutional, and residual) appear to involve dysdifferentiation into myofibroblasts [10-12]. DD is associated with abundance of collagen, fibronectin, integrins, cytokines and many other growth factors $[2,7,13-15]$, as well as altered expression of several genes [16-25], but unlike the involvement of known oncogenes and suppressor genes in cancer development [26], our knowledge of the exact aetiopathogenesis of DD remains poor despite significant understanding of its biology.

Systems biology combines mechanistic modelling with quantitative experimentation in studies of networks [27-34] and aims at understanding how the interaction of multiple components within a cell, tissue, organ or indeed individual leads to much of biological function and obfuscates correlations with single genes. Systemslevel approaches have begun to help comprehension of network control, (dys-)regulation, and function [35-38]. This has improved the understanding of certain disorders [39], and has provided new rationales for drug discovery [40-42]. The complex biology of DD may constitute an invitation to a systems level approach. In this review, we outline such an approach.

\section{Dupuytren's disease and its many faces Histopathology}

Clinical examples of fibrosis include renal interstitial fibrosis [43], scleroderma [44], sarcoidosis [45], idiopathic pulmonary fibrosis [46], retroperitoneal fibrosis [47] and DD [48]. DD tissue shows increased deposition of collagen III relative to collagen I and increased levels of collagen hydroxylation and glycosylation [49]. DD is thought to arise either from a defect in the wound repair process or from an abnormal response to wounding. The presence of immune cells and related phenomena in DD tissue suggests DD may be immune-related [50-53]. 


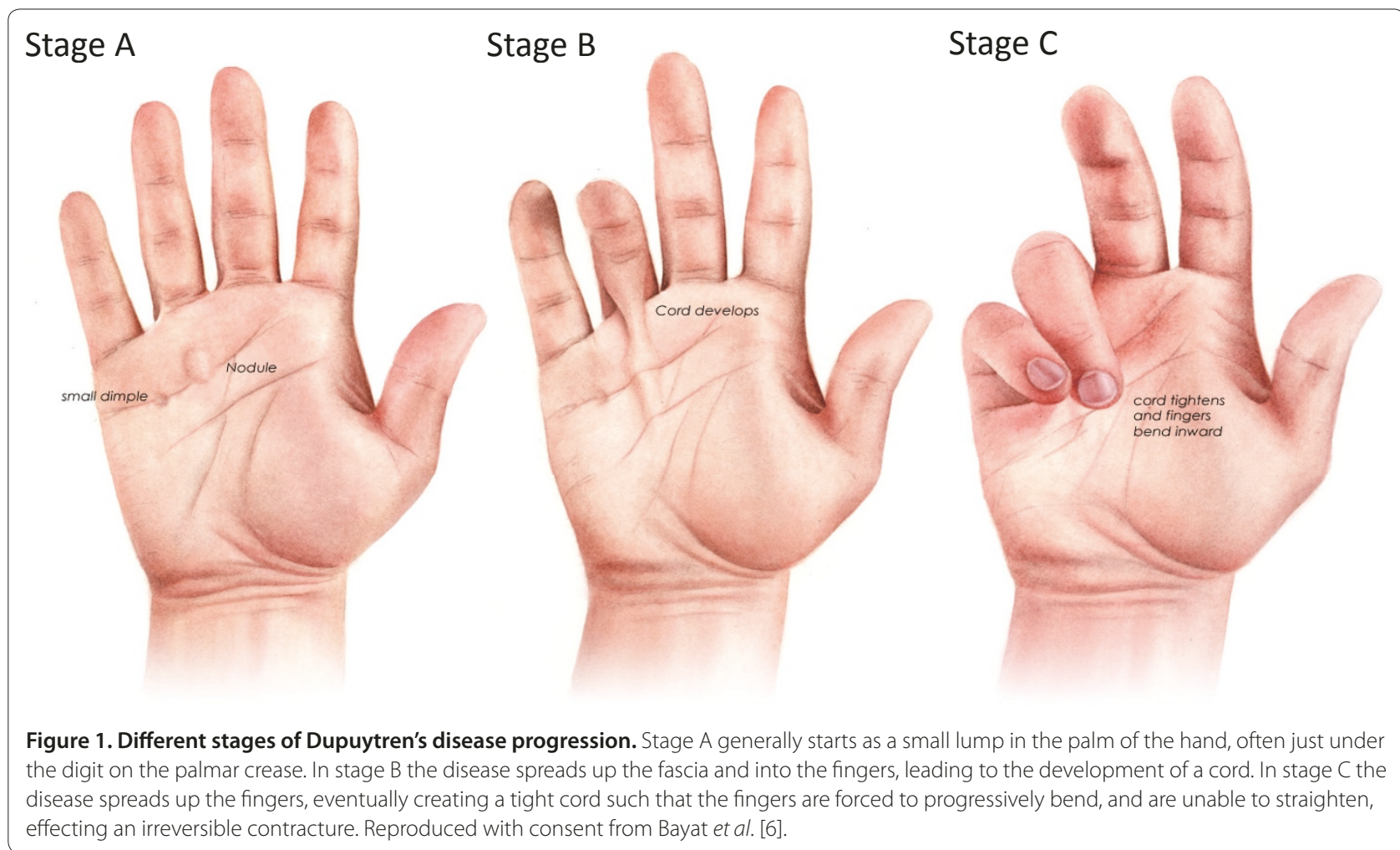

Cellularity (quantified as the cellular density) of the DD nodules (see below) is indicative of the activity of the disease [4]. DD has been classified into three stages coexisting in the same specimen, that is, proliferative, involutional and residual, further subdivided into the essentially fibrous nodules, reactive tissue, and residual tissue. It contains two structurally distinct fibrotic elements: the nodule is a highly vascularised tissue containing many fibroblasts, with a high percentage being recognised as myofibroblasts due to their expression of the $\alpha$ smooth muscle actin; and the cord is relatively avascular, acellular, and collagen-rich with few myofibroblasts. The nodule may develop into the cord as the disease progresses over time or the two structures represent independent stages of the disease. Macroscopically, neither the deep retinacular tissue that includes the transverse palmar ligament or fascia, also known as 'Skoog's fibres', nor the fibrous flexor tendon sheaths appear to be involved in DD. Other areas are affected macroscopically but at irregular depth and distribution, with the more superficial layers and ulnar side of the palm being affected most.

The specialised mesenchymal cells expressing smooth muscle $\alpha$-actin may explain the contractility observed in DD [11,54-56]; they resemble the myofibroblasts of granulation tissue thought to be responsible for contraction during wound healing. The Dupuytren myofibroblast synthesizes fibronectin, an extracellular glycoprotein that connects myofibroblasts and connects them to the extracellular stromal matrix through an integrin.

According to genome-wide gene expression profiles, fibroblasts come in various subtypes [57], perhaps due to 'topographic differentiation'; that is, distinct phenotypes persisted in vitro even when fibroblasts were isolated from the influence of other cell types [58]. Chang et al. [57] did not evaluate diversity or cell heterogeneity in DD. All of those evaluated had the morphology of elongated, spindle-shaped cells. Fibroblast cultures were uniformly positive for a mesenchymal immunofluorescence marker, but negative for markers of epithelial, smooth muscle, endothelial, perineural, and histiocytic cells. Different passages of the same fibroblast culture clustered with each other, indicating that their in vitro phenotypes were stable. Several components implicated as modulators of transdifferentiation of DD fibroblasts into myofibroblasts have been reported [59-69]. Among the cytokines, transforming growth factor- $\beta$ is thought to be a significant inducer of myofibroblast transdifferentiation because of its ability to up-regulate $\alpha$-smooth muscle actin and collagen in fibroblasts, both in vivo and in vitro [65].

\section{Genetics}

A study performed in a five generation Swedish family suggested that DD was inherited in an autosomal dominant pattern [70]. Linkage analysis implicated a single region of approximately $6 \mathrm{cM}$ between markers D16S419 
and D16S3032 at a logarithm of the odds (LOD) score $>1.5$. Genotyping of four siblings affected by the disease but from another branch of the family together with the use of additional microsatellite markers produced a maximal LOD score of 3.2 (for D16S415), with four other markers producing LOD scores $>1.5$. When a disease is dominant, it is likely to be caused by a single allele of a single gene, and by the molecule it encodes. From this perspective, the above findings would suggest that DD is a single gene disease. To date, however, linkage to a single gene has not been reported at a LOD that is much more significant than the marginal value of 3 in this Swedish study and the penetrance in this study was incomplete. In addition, the disease develops at an advanced age, there are many more sporadic cases of DD, and there are few such families for which the genetic analysis has been performed. Indeed, other studies have shown association of the disease with other loci, including a positive association with HLA-DRB1*15 on chromosome 6 in Caucasians [71]. A study of 20 British DD patients with a maternally transmitted inheritance pattern demonstrated a mutation within the mitochondrial genome (mitochondrial $16 \mathrm{~S}$ ribosomal RNA region) in $90 \%$ of patients [72]. The defective mitochondria generated abnormally high levels of free radicals and induced defects in apoptotic mechanisms.

\section{Reactive oxygen species}

A relation between localised ischaemia, reactive oxygen species (ROS) and DD was projected from a study in which palmar fascia from 10 DD individuals were subjected to 0 to 60 minutes of tourniquet ischaemia DD [73]. The concentration of hypoxanthine was six-fold higher in Dupuytren's palmar fascia compared to the palmar fascia from ten suitable control patients (having carpal tunnel decompression), implying that measuring metabolites directly in tissue could help understand DD. Xanthine oxidase catalyzes the removal of hypoxanthine, generating super oxide free radicals and hydrogen peroxide as by-products that would damage the perivascular connective tissue, which fibroblasts would attempt to repair. Upon addition of free radicals to fibroblast cultures from DD palmar fascia, lower concentrations of ROS stimulated fibroblast proliferation, explaining the observed increase in collagen type III [73]. The hypoxanthine was more abundant in nodular areas than in the tight fibrous cords. We propose that microvessel narrowing, leading to localised hypoxic conditions, may be one cause of DD, secondary to age, smoking and other environmental factors as discussed by Shih and Bayat [3].

\section{Transcriptomics}

Alterations of gene expression in Dupuytren's nodules [25], Peyronie's plaques [74], and cultured fibroblasts have been reported. Because of the complexity and heterogeneity of the disease, we carried out a new transcriptome analysis, optimizing for unbiased experimental design, sample size and sufficiently large data sets by considering the nodule and the cord as two separate entities, and by adding a pathway oriented approach. We compared diseased Dupuytren tissue biopsies (both nodules and cords) with corresponding healthy tissue (the transverse palmar fascia adjacent to the diseased site) from the same patients as well as with profiles from the palmar fascia of individuals not affected by DD [18]. The genes we confirmed and established as altered in expression in DD $[13,60]$ are involved in the immune response, angiogenesis, apoptosis, cell adhesion and cellmatrix adhesion, cell cycle and proliferation, cell differentiation, transcription, development, signalling and signal transduction, protein synthesis and folding, oxygen transport, and carbohydrate metabolism (Figure 2). A study comparing fibroblasts isolated from DD patients with those from controls found tens of genes to be altered at the mRNA expression level, although these differed between the two microarray platforms used. The downregulation of three of the genes was confirmed by quantitative PCR; these encode a proteoglycan, a fibulin and type XV collagen alpha 1 chain [75]. Also using PCR, Ulrich and colleagues [76] found that DD tissue amplified mRNA encoding one metalloprotease and two tissue inhibitors of metalloproteases. The genes localised between markers D16S419 and D16S3032 encode hemoglobin $\alpha 1$ and 2, cadherin 11 type 2, OB-cadherin (osteoblast), matrix metallopeptidase 2 , periplakin, tryptase $\alpha / \beta 1$, and tryptase $\beta 2$. The transcriptomics results were therefore not particularly supportive of the early hypothesis that altered expression of a single autosomal gene on chromosome 16 is solely responsible for DD. The observation that genes with fairly obvious functional connections to DD, such as those encoding metalloproteases, proteoglycans and collagen components, have altered expression brings home the message that even if the disease were to have a singlegene origin, its aetiology is likely to involve multiple regulatory pathways and genes downstream. Up to now the hunt for the single DD gene has not only failed but also weakened its own motivation; many genes, both upstream and downstream, may be involved in causing DD.

\section{Proteomics}

The DD proteomics venture began in 2006 with the study of protein expression profiles in an attempt to identify potential disease biomarkers $[77,78]$. In one study, twodimensional gel electrophoresis was performed to extract proteins from diseased tissue (nodule and cord), the Skoog's fibres, and normal control tissues. MALDI-TOFMS (matrix-assisted laser desorption ionization time-offlight mass spectrometry) generated a peptide mass 


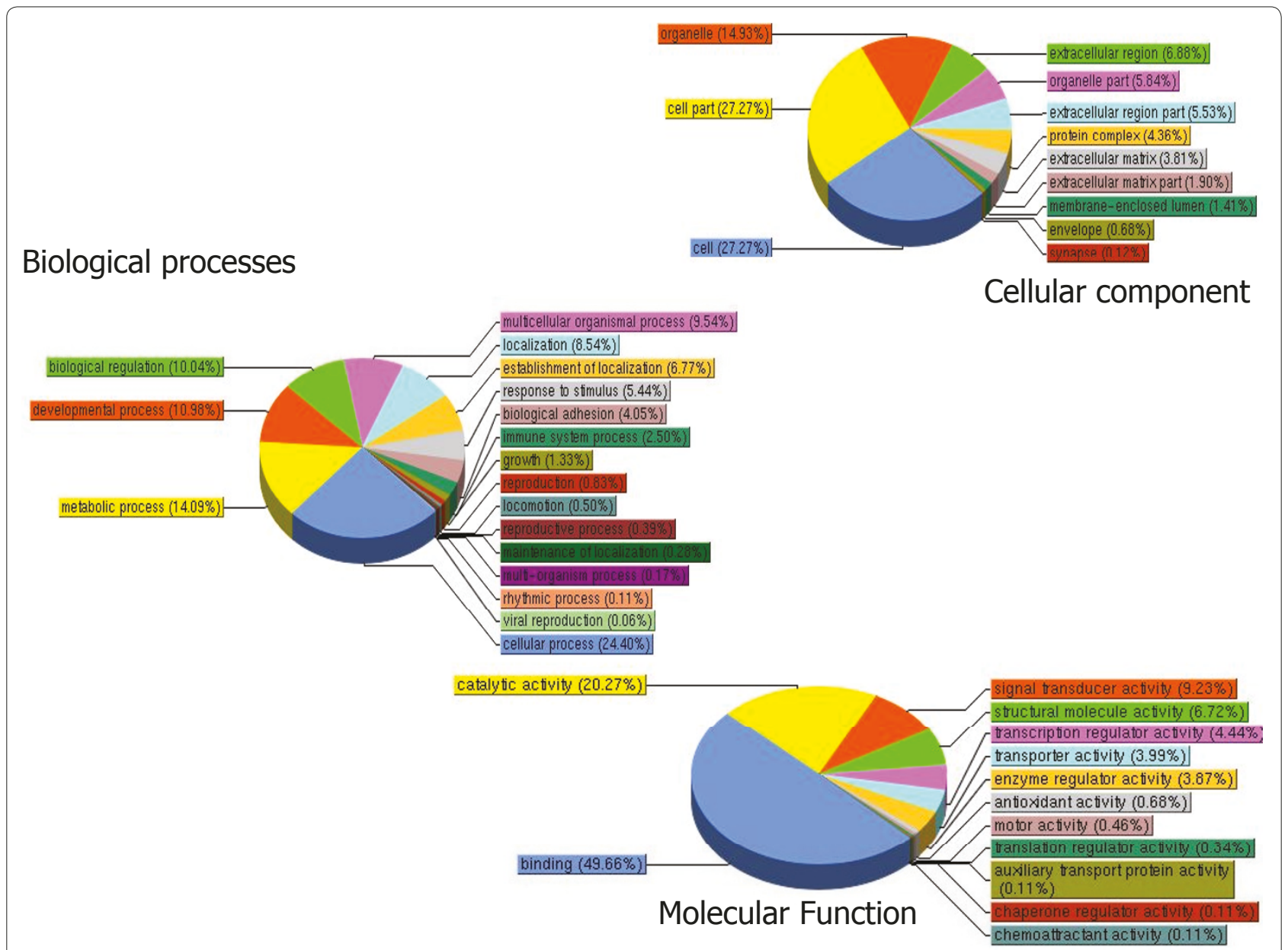

Figure 2. Cellular components, molecular functions and biological processes associated with Dupuytren's disease as derived from gene expression studies [18] using Gene Ontology.

fingerprint that was used to search protein databases; however, the authors did not report names of identified proteomic changes in their abstract. SELDI-TOF-MS (surface enhanced laser desorption/ionization time-offlight mass spectrometry) using Ciphergen's SELDI-TOFMS Protein Biological System II (PBSII) ProteinChip reader [78] revealed several differentially expressed low molecular weight $(<20 \mathrm{kDa})$ tissue proteins and identified three disease-associated protein features $(4,600.8 \mathrm{Da}$, 10,254.5 Da, and 11,405.1 Da) that were elevated (5-, 12-, and 4-fold, respectively). Three potential low molecular weight protein markers (p4.6DC, p1ODC, p11.7DC) for $\mathrm{DD}$ were identified. An integrative proteomic-interactomic approach [79] coupling two-dimensional gel electrophoresis with mass spectrometry compared the proteomic profile of DD tissue with that of unaffected patient-matched palmar fasciae tissue and found several proteins correlated with DD. The findings were used to create a protein-protein interaction network (interactome) map on the basis of the proposed interactions in the
Human Interactome Map (HiMAP) [80] and the Search Tool for the Retrieval of Interacting Proteins (STRING) [81]; however, several proteins were added to fill gaps in order to yield a complete network, which then involved extra- and intracellular signalling, oxidative stress, cytoskeletal changes, and alterations in cellular metabolism. In particular, ERBB-2 and insulin-like growth factor 1 receptor (IGF-1R) and the Akt signalling pathway emerged as novel components of pro-survival signalling in Dupuytren's fibroblasts. One should exercise care, however, not to over-interpret these results, as they are partly based on inference from other protein interaction data obtained in different contexts. In addition, increased activity of pathways need not involve increased protein levels [82] and increased pathway expression may be homeostatic rather than aetiological.

The dilemma: more or less data - less or more understanding As more and more aspects associating with DD are revealed, we see less and less forest (understanding of the 
disease) for the trees (its many molecules) [83]. Even if the disease were set in motion by a single genetic factor, its aetiology would involve many diverse processes such that DD will be co-determined by the many factors that regulate those processes. If indeed the networks governing differentiation of normal fibrocytes of the palm of the hand are perturbed irreversibly so that they differentiate into muscle-like tissue without the proper controllers of contraction and relaxation, then different sets of genetic perturbations could lead to DD. In this context DD may be much like cancer [39].

The dilemma is that although we now have an unprecedented set of methodologies for the identification and analysis of all the molecules in living cells, that methodology alone is not enough. We need something substantially more to understand how all those molecules interact to create functional networks. Seeing more molecules may not help our understanding; seeing the connections between them and more mechanism might.

\section{Systems biology disease versus molecular disease}

The disease in Figure 3a may seem to depend on a single molecule (gene) only, or at least that is how it is often conceived. But of course, a disease cannot depend on a gene (if defined as the corresponding DNA sequence) alone: it will depend on its gene product ( $\mathrm{F}$ in Figure 3a), and in fact on the molecular function of the latter. For instance, a muscular dystrophy could result from a mutation in the gene encoding myosin, the molecular function of which is muscle contraction. If that muscular dystrophy were only found when the myosin gene has been mutated and if the severity of the disease was not influenced by other factors, then that muscular dystrophy would be a single-gene disease. In actuality there are many different genetic lesions that lead to similar muscular dystrophies, including lesions in mitochondrially encoded genes [84]. A better candidate for a mono-gene disease may be phenylketonuria, an inherited (autosomal recessive) metabolic disease that is largely due to mutations in the phenylalanine hydroxylase $(P A H)$ gene [85]. However, its therapy (dietary restriction) shows that the disease can be influenced by external factors, mutations in genes involved in the synthesis of a cofactor of the phenylalanine hydroxylation reaction also lead to the disease, and there are multiple alleles of the $P A H$ gene that confer different severities. Hence, even this disease exhibits characteristics of systems biology diseases.

Most diseases have multiple genes associated with them. Such diseases might be considered to be a group of single-gene diseases; that is, many different diseases each being caused by a different single gene lesion, but all with similar phenotypes [86]. This would explain the association of multiple genes with the disease. In the case of a group of single gene diseases, no other faulty molecules should be important for that individual disease and no other gene changes (for example, polymorphisms) or conditions (for example, diet) should influence the disease severity. Notably, a single patient's transcriptome should then show only changes in the single molecular culprit and not in other factors controlling the network leading to the disease; and in the transcriptomes of different patients suffering from the same disease group, that single molecular culprit should be different. For DD this is not what is observed (see above). As illustrated in Figure $3 \mathrm{~b}$, in a systems biology disease the function that is compromised depends cooperatively on a number of pathways, the functioning of each of which again depends on many cooperating molecular factors. In systems biology diseases one would typically find multiple changes in the transcriptome or proteome of each patient, differing between individual patients but such that all have a very similar disabling effect on network function. Identifying a disease as a systems biology or network disease does not dispel molecules from its pathology: molecules are always involved. The issue is whether the change in networking of the molecules is crucial for the disease, that is, whether the disease is more a consequence of faulty networking than of an individual malfunctioning molecule.

What difference should this all make for research, diagnosis and therapy? The answer is straightforward: when dealing with a network disease, one should deal with the network; when dealing with a molecular disease, one should concentrate on the molecule. For systems biology diseases, transcriptome patterns should be mapped onto the known cellular pathways, network fluxes, and the disease. The concept 'candidate pathway' or even 'candidate network' should be substituted for 'candidate gene.' In addition, one should investigate at the proteome, metabolome, and functional levels [87], and not each independently but all together, and then one may need to examine multiple network functions (Figure 4). Malignant cancer, for instance, may involve proliferation, lack of apoptosis, metastasis and multiple drug resistances.

\section{Is Dupuytren's disease a single-molecule or a systems biological disease?}

DD has been identified as a disease inherited in an autosomal dominant pattern [70] (and see above). It was linked to a single $6 \mathrm{cM}$ region on chromosome 16. This would suggest that all DD patients should have a mutation in this part of their genome, and that transcriptomes of DD patients should be altered in terms of the level of the transcripts encoded by this part of the genome or in terms of the coding sequence of one of those transcripts. However, the dominance was 


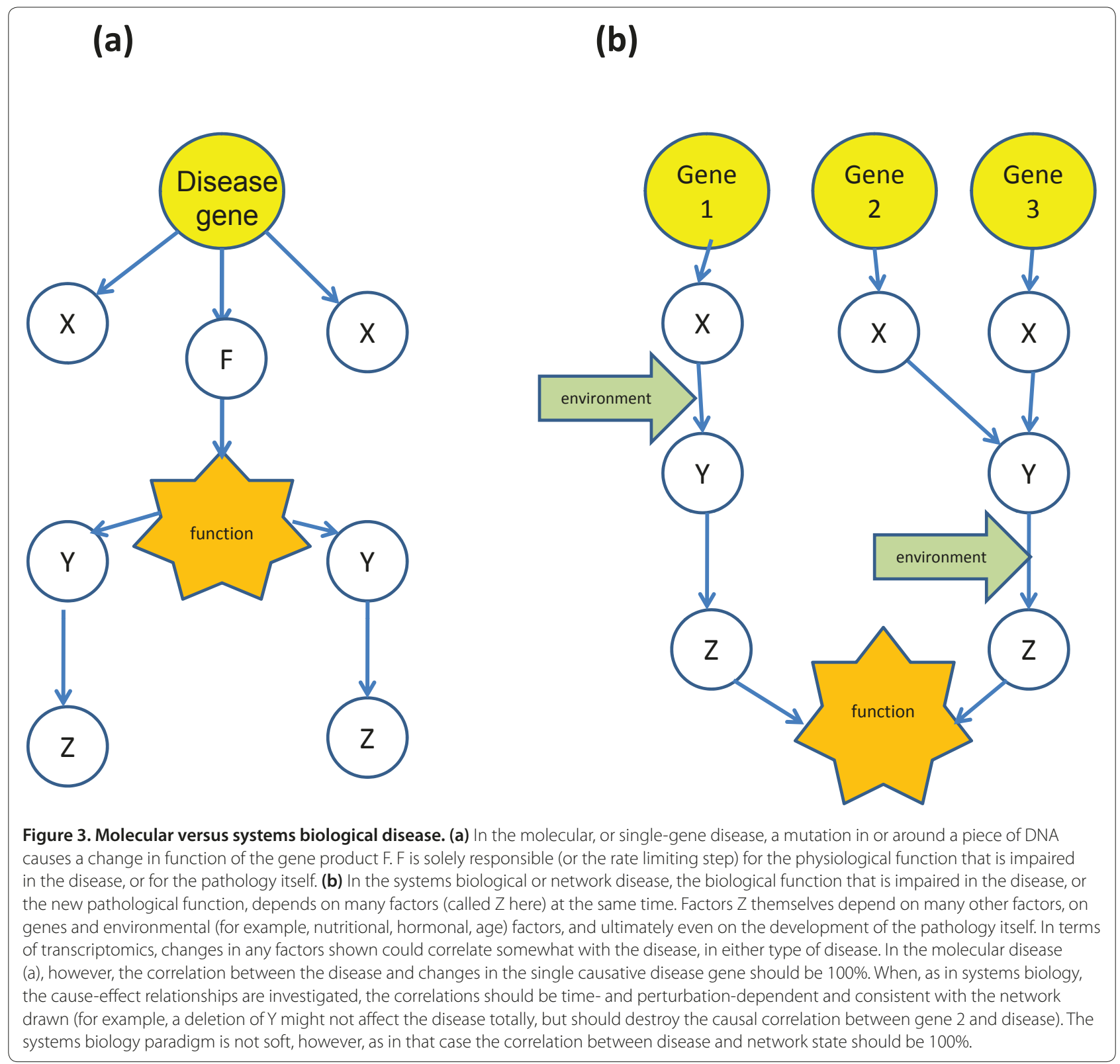

incomplete, weak, and has only been observed in a single Swedish family. This suggests that the genes on chromosome 16 are only dominant when other genes in the genome are of certain allelic forms. Moreover, in many other cases the expression levels of many other mRNAs were changed, although it remains to be analyzed whether in those studies there was always a change in mRNAs from the $6 \mathrm{cM}$ region on chromosome 16. In our own studies, DD nodule transcriptomes of individual patients have all exhibited multiple changes in mRNA levels, and although these changes overlapped, they were not identical between individuals. The proteome did not point to a single causative protein either. The functional studies pointed to myofibroblast enrichment, although not clearly as the sole cause, and neither was a causal relationship between a gene on chromosome 16 in the $6 \mathrm{cM}$ region and differentiation of myofibroblasts established. This all shows that DD is not a single-gene disease and suggests that it is not just a group of pure single-gene diseases either. It is much more likely to be a systems biology disease.

\section{Treatment}

Surgical intervention is still the current mainstay of treatment for DD, usually involving fasciotomy, fasciectomy or dermofasciectomy [88]. A variety of non-operative techniques have been practiced but have failed to give long-lasting benefits. More recently, clinical 


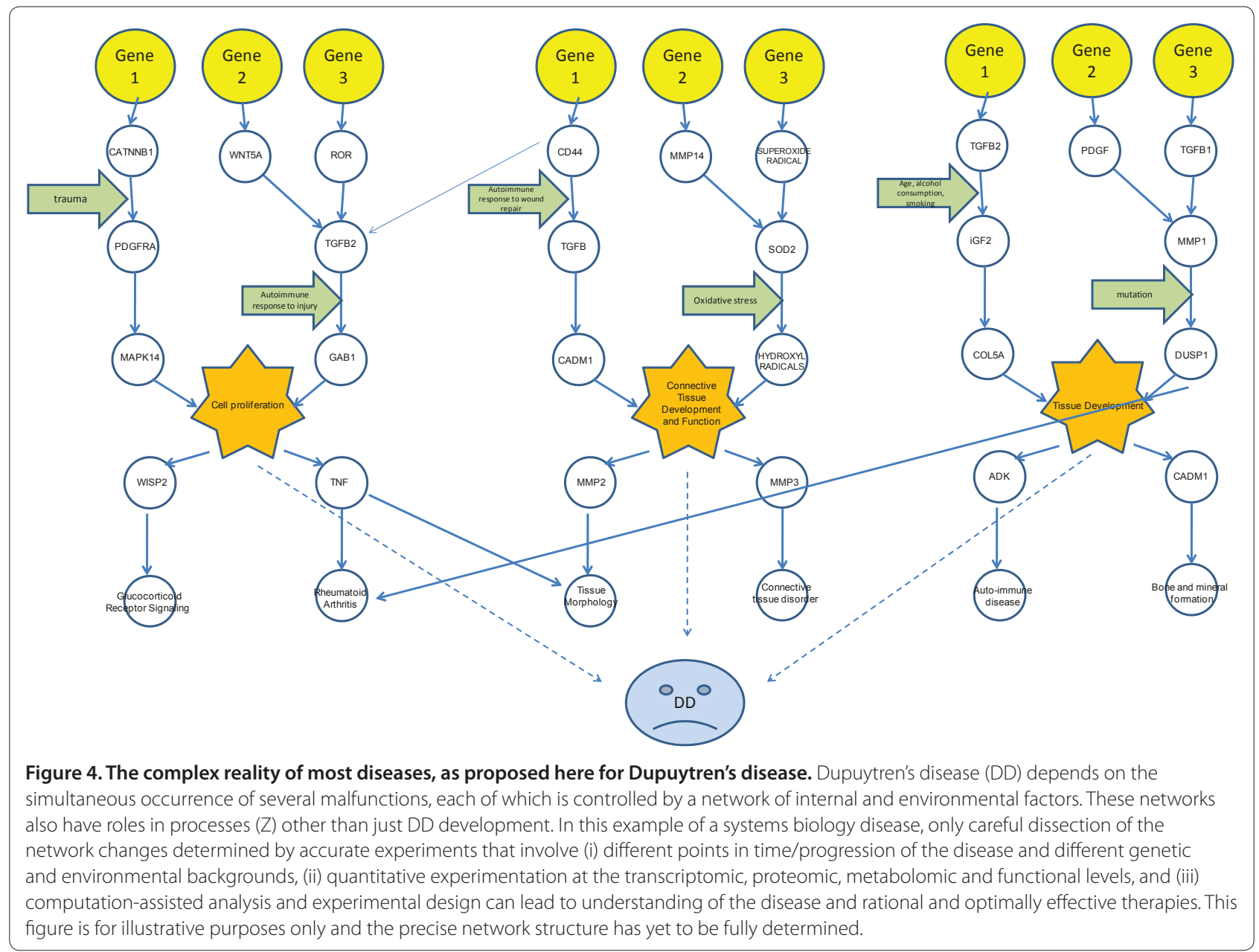

investigation (phase II and III), including the use of clostridial collagenase injections, have shown encouraging results in some DD patients $[89,90]$, but long-term follow-up results are required before this can be advocated as standard procedure in place of surgery.

\section{Conclusion}

Since association of DD with a single gene is inconclusive, the present mainstream research paradigm may be unlikely to lead to a full understanding of it. The experimental data appear to be more consistent with DD being a systems biology disease. Therefore, a different approach to the disease should be considered; analysis, diagnosis and therapy should target pathways rather than genes or their products. The concept of a 'candidate gene' should be replaced with that of 'candidate pathway(s)'. Studies should be aimed at elucidating cause-effect chains, rather than disease correlations. From the experimental data, alterations in pathways should be inferred. Using transgenic and antisense approaches in cell lines, these pathway alterations should then be induced and the predicted development into a DD cellular phenotype tested. The pathways are expected to be integrals of gene expression, signalling and metabolic networks, as should be the approach and data analysis.

A hypothesis-driven systems biology would be based on a priori observations in human, in vitro or in vivo (linkage and expression studies, for example), or on knowledge of related diseases (such as plantar fibromatosis, peyronies, musculo-aponeurotic fibromatosis and even keloid disease). Inter-relationships would be sought between hypothesized underlying mechanisms governing these fibrotic disorders and physiological changes predicted based on molecular and environmental changes impacting on those mechanisms. This could then be extended to understand inter- versus intra-individual variability. Altering the networks using multiple molecular interventions in a tissue culture model system for DD would enable the hypotheses to be tested.

Such an approach should also help put into perspective existing inconclusive discoveries and maximize the utilization of data obtained from molecular approaches 


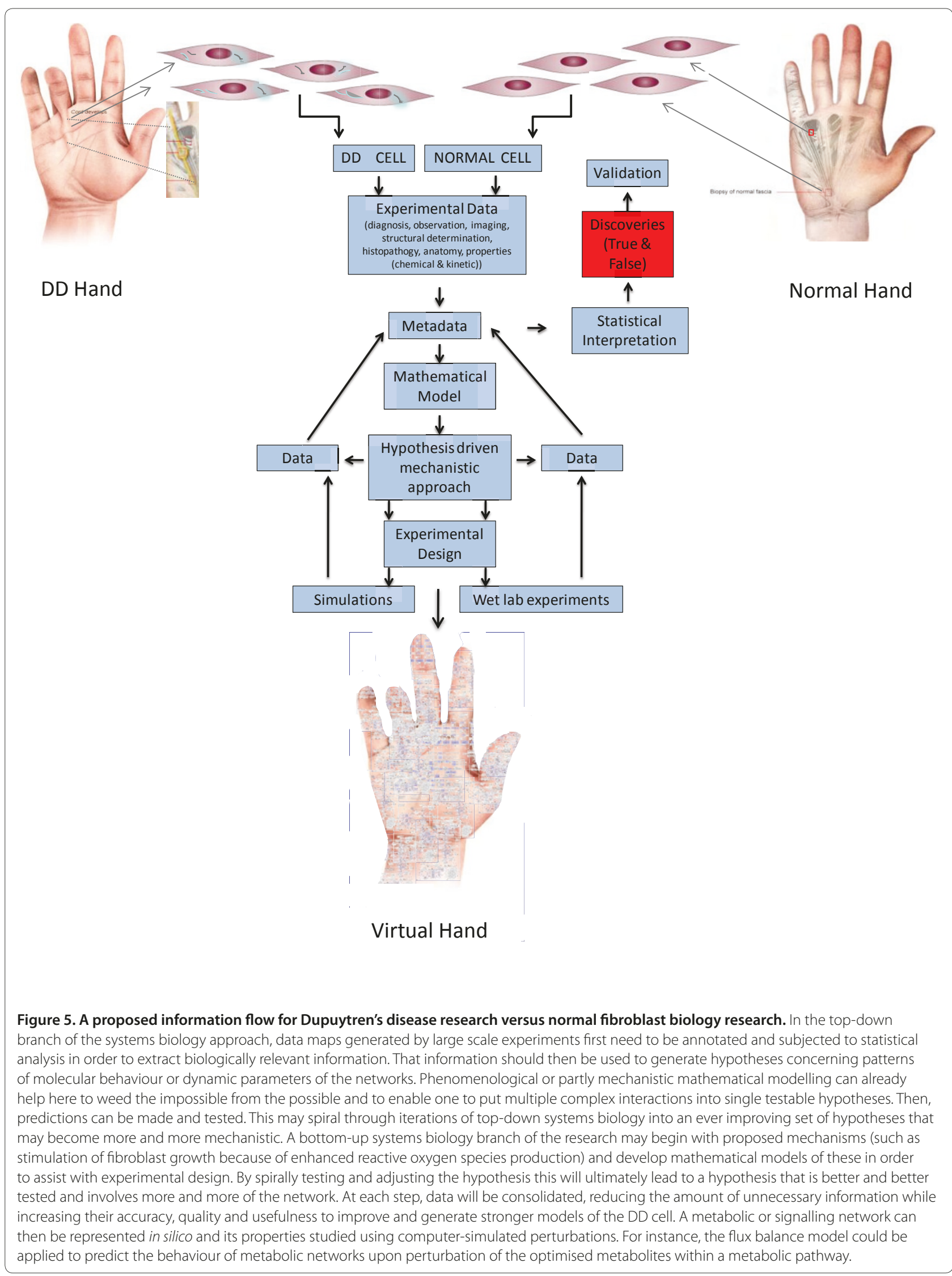


from molecular biology, perhaps in the sense of a live model repository [91]. Indeed, omics experiments generate heterogeneous data and metadata torrents. Systems biology modelling would serve as a way to organize the data rationally and efficiently. Emerging standard languages, such as the Systems Biology Markup Language (SBML) [92], Cell Markup Language (CellML) [93], Cell System Markup Language (CSML) [94], Biological Pathway Exchange (BioPAX) [95] and Systems Biology Graphical Notation (SBGN) [96], and modelling tools such as COmplex PAthway SImulator (COPASI) [97], Cytoscape [98] and Pathway databases (for example, Ingenuity pathway analysis software) facilitate data representation and inter-operability from leading multidisciplinary research groups [99]. Additionally, the Java Web Simulation (JWS) facility, which quality controls kinetic models and puts them into a live repository, enables through-web experimentation in silico for scientists naive with respect to modelling, although it is experimentdependent [100]. BioModels is a parallel model repository not built for in silico experimentation but focusing on annotation [101].

If we are right, and the systems biology research paradigm is adopted, the rewards should be substantial: no longer will the data collected in this field disappear into the diaspora of the experimental literature; they will be analyzed in terms of network models and, when informative, connected with proper data annotation [102]. Once the network hypotheses are proven, they will underpin the development of new rational biomarker strategies, and become the starting point for potential therapeutic interventions and prophylaxis.

More concretely, even though myofibroblasts obtained from different stages of DD may exhibit features that could trigger contraction and uncontrollable growth, neither the diversity of these cells nor the extent or nature of their local specificity in situ with regard to differentiation have been examined systematically. Remodelling of vascular connective tissue should be of fundamental importance as DD progresses over time and the ability of that tissue to be remodelled could be an important factor in the development of the disease. Matrix remodelling and matrix turnover are controlled by a complex network of cell-cell and cell-matrix interactions [103]. Mathematical modelling of these networks combined with targeted experimentation should help deduce the net outcome of the balance between proliferative and degradative processes.

Together, genomics, transcriptomics, proteomics, fluxomics, lipidomics, interactomics, glycomics and secretomics studies of biofluids within the DD system have the potential to improve our understanding of the disease immeasurably [104-106]; however, the 'together' concept requires an integration that is only plausible through systems approaches.
Investigating this complex deforming fibromatosis as part of a systems biology approach (Figure 5) will benefit not only understanding of the specific diseased phenotypes, but may also address the effects on the extracellular matrix and excreted by-products, and could offer further suggestions for early diagnosis.

Recognition of DD as a systems biology disease should also affect therapy. Treatment need not target the reversal of a molecular event but rather return a network affected by a combination of molecular culprits (for example, resulting from single-nucleotide polymorphisms) to its normal state. This return may be attempted by interventions in the network that may otherwise be unrelated to the molecular culprits. In this sense the recognition that DD is a network disease should increase the number of treatment options. More specifically, one should look at a number of intracellular networks (metabolic, signal transducing, or otherwise) affecting the disease and then consider treatment with combinations of existing drugs (and behavioural advice) that target all those networks. The relative dosages should be optimized, allowing for the optimum to differ between patients.

\section{Abbreviations}

DD, Dupuytren's disease; LOD, logarithm of the odds; ROS, reactive oxygen species.

\section{Competing interests}

The authors declare that they have no competing interests.

\section{Acknowledgements}

SR thanks BBSRC and EPSRC for her studentship via the Doctoral Training Centre, at the Manchester Centre for Integrative Systems Biology, UK. HW [http://www.systembiology.net/support/] and RG thank various funders but in particular the EPSRC and BBSRC for their support of the above two centres.

\section{Author details}

'Manchester Centre for Integrative Systems Biology, Manchester Interdisciplinary Biocentre, University of Manchester, Manchester, M1 7DN, UK. ${ }^{2}$ School of Chemistry, Manchester Interdisciplinary Biocentre, University of Manchester, Manchester, M1 7DN, UK. ${ }^{3}$ Quantitative Molecular Medicine Research, CIGMR, Manchester Interdisciplinary Biocentre, University of Manchester, Manchester, M1 7DN, UK. "Plastic and Reconstructive Surgery Research, Manchester Interdisciplinary Biocentre, University of Manchester, Manchester, M1 7DN, UK. ${ }^{5}$ Netherlands Institute for Systems Biology, VU University Amsterdam, NL-1081 HV, The Netherlands.

Published: 12 September 2011

\section{References}

1. McFarlane RM, Flint MH: Dupuytren's Disease: Biology and Treatment. New York: Churchill Livingstone; 1990

2. Rayan GM: Dupuytren disease: anatomy, pathology, presentation, and treatment. J Bone Joint Surg Am 2007, 89:189-198.

3. Shih B, Bayat A: Scientific understanding and clinical management of Dupuytren's disease. Nat Rev Rheumatol 2010, 6:715-726.

4. Meyerding HW, Black JR, Broders AC: The etiology and pathology of Dupuytren's contracture. Surg Gynecol Obstetric 1941, 72:582-590.

5. Seemayer TA, Lagacé R, Schürch W, Thelmo WL: The myofibroblast: biologic, pathologic, and theoretical considerations. Pathol Annu 1980, 15(Pt 1):443-470

6. Bayat A, McGrouther DA: Management of Dupuytren's disease - clear advice for an elusive condition. Ann R Coll Surg Eng/2006, 88:3-8.

7. Shaw RB, Chong AKS, Zhang A, Hentz VR, Chang J: Dupuytren's disease: history, diagnosis, and treatment. Plast Reconstr Surg 2007, 120:44e-54e. 
8. Hindocha S, Stanley JK, Watson S, Bayat A: Dupuytren's diathesis revisited: evaluation of prognostic indicators for risk of disease recurrence. $J$ Hand Surg Am 2006, 31:1626-1634.

9. Hayton MJ, Gray ICM: Dupuytren's contracture: a review. Curr Orthopaed 2003, 17:1-7.

10. Tse R, Howard J, Wu Y, Gan B: Enhanced Dupuytren's disease fibroblast populated collagen lattice contraction is independent of endogenous active TGF-beta2. BMC Musculoskelet Disord 2004, 5:41.

11. Drake MJ, Hedlund P, Andersson KE, Brading AF, Hussain I, Fowler C, Landon DN: Morphology, phenotype and ultrastructure of fibroblastic cells from normal and neuropathic human detrusor: Absence of myofibroblast characteristics. J Urol 2003, 169:1573-1576

12. Moyer KE, Banducci DR, Graham WP, Ehrlich HP: Dupuytren's disease: physiologic changes in nodule and cord fibroblasts through aging in vitro. Plast Reconstr Surg 2002, 110:187-193.

13. Lubahn JD, Pollard M, Cooney T: Immunohistochemical evidence of nerve growth factor in Dupuytren's diseased palmar fascia. J Hand Surg Am 2007, 32:337-342

14. Clozel $\mathrm{M}$, Salloukh $\mathrm{H}$ : Role of endothelin in fibrosis and antifibrotic potential of bosentan. Ann Med 2005, 37:2-12

15. Cordova A, Tripoli M, Corradino B, Napoli P, Moschella F: Dupuytren's contracture: an update of biomolecular aspects and therapeutic perspectives. J Hand Surg Br 2005, 30:557-562.

16. Hnanicek J, Cimburova M, Putova I, Svoboda S, Stritesky J, Kratka K, Sosna B, Horak J: Lack of association of iron metabolism and Dupuytren's disease. $J$ Eur Acad Dermatol Venereol 2008, 22:476-480.

17. Kaur S, Forsman M, Ryhänen J, Knuutila S, Larramendy ML: No gene copy number changes in Dupuytren's contracture by array comparative genomic hybridization. Cancer Genet Cytogenet 2008, 183:6-8.

18. Rehman S, Salway F, Stanley JK, Ollier WER, Day P, Bayat A: Molecular phenotypic descriptors of Dupuytren's disease defined using informatics analysis of the transcriptome. J Hand Surg Am 2008, 33:359-372.

19. Forsman $M$, Paakkonen $V$, Tjaderhane L, Vuoristo J, Kallioinen L, Salo T, Kallioinen M, Ryhanen J: The expression of myoglobin and ROR2 protein in Dupuytren's disease. J Surg Res 2008, 146:271-275.

20. Johnston P, Chojnowski AJ, Davidson RK, Riley GP, Donell ST, Clark IM: A complete expression profile of matrix-degrading metalloproteinases in Dupuytren's disease. J Hand Surg Am 2007, 32:343-351.

21. Lee LC, Zhang AY, Chong AK, Pham H, Longaker MT, Chang J: Expression of a novel gene, MafB, in Dupuytren's disease. J Hand Surg Am 2006, 31:211-218.

22. O'Gorman D, Wu Y, Seney S, Zhu R, Gan B: Wnt expression is not correlated with beta-catenin dysregulation in Dupuytren's disease. J Negat Results Biomed 2006, 5:13

23. Samuel CS, Hewitson TD: Relaxin in cardiovascular and renal disease. Kidney Int 2006, 69:1498-1502.

24. Maureen DM: Endothelin and endothelin receptor antagonists in systemic rheumatic disease. Arthritis Rheum 2003, 48:1190-1199.

25. Pan D, Watson HK, Swigart C, Thomson JG, Honig SC, Narayan D: Microarray gene analysis and expression profiles of Dupuytren's contracture. Ann Plast Surg 2003, 50:618-622.

26. Hanahan D, Weinberg RA: The hallmarks of cancer. Cell 2000, 100:57-70.

27. Kholodenko BN, Kiyatkin A, Bruggeman FJ, Sontag E, Westerhoff HV, Hoek JB: Untangling the wires: a strategy to trace functional interactions in signaling and gene networks. Proc Natl Acad Sci U S A 2002, 99:12841-12846.

28. An G, Hunt CA, Clermont $G$, Neugebauer E, Vodovotz Y: Challenges and rewards on the road to translational systems biology in acute illness: four case reports from interdisciplinary teams. J Crit Care 2007, 22:169-175.

29. Westerhoff HV, Palsson BO: The evolution of molecular biology into systems biology. Nat Biotechnol 2004, 22:1249-1252.

30. Ahn AC, Tewari M, Poon C-S, Phillips RS: The limits of reductionism in medicine: could systems biology offer an alternative? PLoS Med 2006, 3:e208.

31. Katagiri F: Attacking complex problems with the power of systems biology. Plant Physiol 2003, 132:417-419.

32. Spivey A: Systems biology: the big picture. Environ Health Perspect 2004, 112: A938-A943.

33. Jensen PR, Gugten AAvd, Bier M, Heeswijk WCv, Rohwer JM, Molenaar D, Workum Mv, Richard P, Teusink B, Bakker BM, Kholodenko, Westerhoff HV: Hierarchies in control. J Biol Systems 1995, 3:139-144.

34. Kahn D, Westerhoff HV: Control theory of regulatory cascades. J Theor Biol $1991,153: 255-285$
35. Steven Wiley H, Shvartsman SY, Lauffenburger DA: Computational modeling of the EGF-receptor system: a paradigm for systems biology. Trends Cell Biol 2003, 13:43-50

36. Schoeberl B, Gaudet S, Albeck JG, Janes K, Sorger PK, Lauffenburger DA: The apoptotic decision process in TNF alpha-stimulated HT-29 cells: a combined computational and experimental approach. Mol Biol Cell 2002, 13:11A-A.

37. Daran-Lapujade P, Rossell S, van Gulik WM, Luttik MA, de Groot MJ, Slijper M, Heck AJ, Daran JM, de Winde JH, Westerhoff HV, Pronk JT, Bakker BM: The fluxes through glycolytic enzymes in Saccharomyces cerevisiae are predominantly regulated at posttranscriptional levels. Proc Natl Acad Sci US A 2007, 104:15753-15758.

38. Westerhoff HV: Signalling control strength. J Theor Bio/ 2008, 252:555-567.

39. Hornberg JJ, Bruggeman FJ, Westerhoff HV, Lankelma J: Cancer: a systems biology disease. Biosystems 2006, 83:81-90.

40. Boshoff HI, Barry CE, Hornberg J, Bruggeman F, Bakker B, Westerhoff H: Metabolic control analysis to identify optimal drug targets. In Systems Biological Approaches in Infectious Diseases. Edited by Boshoff HI, Barry CE. Birkhäuser Basel; 2007:171-189. [Progress in Drug Research, vol. 64].

41. Bakker BM, Assmus HE, Bruggeman F, Haanstra JR, Klipp E, Westerhoff H: Network-based selectivity of antiparasitic inhibitors. Mol Biol Rep 2002, 29:1-5.

42. Westerhoff HV, Mosekilde E, Noe CR, Clemensen AM: Integrating systems approaches into pharmaceutical sciences. Eur J Pharm Sci 2008, 35:1-4.

43. Eddy A: Interstitial macrophages as mediators of renal fibrosis. Exp Nephrol 1995, 3:76-79.

44. Almeida I, Faria R, Vita P, Vasconcelos C: Systemic sclerosis refractory disease: From the skin to the heart. Autoimmun Rev 2011 [Epub ahead of print].

45. Hunninghake G: Sarcoidosis: linking inflammation and fibrosis. Am J Med Sci 1995, 309:124-133.

46. Selman M, Pardo A, Kaminski N: Idiopathic pulmonary fibrosis: aberrant recapitulation of developmental programs? PLoS Med 2008, 5:e62.

47. Vaglio A, Salvarani C, Buzio C: Retroperitoneal fibrosis. The Lancet 2006, 367:241-251.

48. Hindocha S, John S, Stanley JK, Watson SJ, Bayat A: The heritability of Dupuytren's disease: familial aggregation and its clinical significance. $J$ Hand Surg Am 2006, 31:204-210.

49. Fitzgerald AMP, Kirkpatrick JJR, Naylor IL: Dupuytren's disease - the way forward? J Hand Surg Br 1999, 24:395-399.

50. Andrew JG, Andrew SM, Ash A, Turner B: An investigation into the role of inflammatory cells in Dupuytren's disease. J Hand Surg 1991, 16 B:267-271.

51. Sugden $P$, Andrew JG, Andrew SM, Freemont AJ: Dermal dendrocytes in Dupuytren's disease: a link between the skin and pathogenesis? J Hand Surg 1993, 18 B:662-666.

52. Baird KS, Alwan WH, Crossan JF, Wojciak B: T-cell-mediated response in Dupuytren's disease. Lancet 1993, 341:1622-1623.

53. Gudmundsson KG, Arngrimsson R, Arinbjarnarson S, Olafsson A, Jonsson T: $\mathrm{T}$ - and B-lymphocyte subsets in patients with Dupuytren's disease. Correlations with disease severity. J Hand Surg 1998, 23 B:724-727.

54. Gabbiani G, Majno G: Dupuytren's contracture: fibroblast contraction? An ultrastructural study. Am J Pathol 1972, 66:131-146.

55. Tomasek JJ, Gabbiani G, Hinz B, Chaponnier C, Brown RA: Myofibroblasts and mechano-regulation of connective tissue remodelling. Nat Rev Mol Cell Biol 2002, 3:349-363.

56. Tomasek JJ, Vaughan MB, Haaksma CJ: Cellular structure and biology of Dupuytren's disease. Hand Clin 1999, 15:21-34.

57. Chang HY, Chi JT, Dudoit S, Bondre C, Van De Rijn M, Botstein D, Brown PO: Diversity, topographic differentiation, and positional memory in human fibroblasts. Proc Natl Acad Sci U S A 2002, 99:12877-12882.

58. Kaufman L, Rousseeuw P: Finding Groups in Data: An Introduction to Cluster Analysis (Wiley Series in Probability and Statistics). Wiley-Interscience; 2005.

59. Iwasaki H, Müller H, Stutte HJ, Brennscheidt U: Palmar fibromatosis (Dupuytren's contracture). Ultrastructural and enzyme histochemical studies of 43 cases. Virchows Arch A Pathol Anat Histopathol 1984, 405:41-53.

60. Kloen P: New insights in the development of Dupuytren's contracture: a review. Br J Plastic Surg 1999, 52:629-635.

61. Alioto RJ, Rosier RN, Burton RI, Edward Puzas J: Comparative effects of growth factors on fibroblasts of Dupuytren's tissue and normal palmar fascia. J Hand Surg Am 1994, 19:442-452.

62. Badalamente MA, Hurst LC, Grandia SK, Sampson SP: Platelet-derived growth factor in Dupuytren's disease. J Hand Surg Am 1992, 17:317-323. 
63. Badalamente MA, Sampson SP, Hurst LC, Dowd A, Miyasaka K: The role of transforming growth factor beta in Dupuytren's disease. J Hand Surg 1996, 21:210-215

64. Bayat A, Alansar A, Hajeer AH, Shah M, Watson JS, Stanley JK, Ferguson MWJ, Ollier WER: Genetic susceptibility in Dupuytren's disease: lack of association of a novel transforming growth factor beta(2) polymorphism in Dupuytren's disease. J Hand Surg Br 2002, 27 B:47-49.

65. Vaughan MB, Howard EW, Tomasek JJ: Transforming growth factor-[beta]1 promotes the morphological and functional differentiation of the myofibroblast. Exp Cell Res 2000, 257:180-189.

66. Berndt A, Kosmehl H, Mandel U, Gabler U, Luo X, Celeda D, Zardi L, Katenkamp D: TGF and bFGF synthesis and localization in Dupuytren's disease (nodular palmar fibromatosis) relative to cellular activity, myofibroblast phenotype and oncofetal variants of fibronectin. Histochem J 1995, 27:1014-1020.

67. Lappi DA, Martineau D, Maher PA, Florkiewicz RZ, Buscaglia M, Gonzalez AM, Farris J, Hamer M, Fox R, Baird A: Basic fibroblast growth factor in cells derived from Dupuytren's contracture: synthesis, presence, and implications for treatment of the disease. J Hand Surg Am 1992, 17:324-332.

68. Gonzalez AM, Buscaglia M, Fox R, Isacchi A, Sarmientos P, Farris J, Ong M, Martineau D, Lappi DA, Baird A: Basic fibroblast growth factor in Dupuytren's contracture. Am J Pathol 1992, 141:661-671.

69. Serini G, Gabbiani G: Mechanisms of myofibroblast activity and phenotypic modulation. Exp Cell Res 1999, 250:273-283.

70. Hu FZ, Nystrom A, Ahmed A, Palmquist M, Dopico R, Mossberg I, Gladitz J, Rayner M, Post JC, Ehrlich GD, Preston RA: Mapping of an autosomal dominant gene for Dupuytren's contracture to chromosome $16 \mathrm{q}$ in a Swedish family. Clin Genet 2005, 68:424-429

71. Brown JJ, Ollier W, Thomson W, Bayat A: Positive association of HLADRB1*15 with Dupuytren's disease in Caucasians. Tissue Antigens 2008, 72:166-170.

72. Bayat A, Walter J, Lambe H, Watson JS, Stanley JK, Marino M, Ferguson MWJ, Ollier WER: Identification of a novel mitochondrial mutation in Dupuytren's disease using multiplex DHPLC. Plast Reconstr Surg 2005, 115:134-141.

73. Murrell GA, Francis MJ, Bromley L: Free radicals and Dupuytren's contracture. Br Med J (Clin Res Ed) 1987, 28:1373-1375.

74. Qian A, Meals RA, Rajfer J, Gonzalez-Cadavid NF: Comparison of gene expression profiles between Peyronie's disease and Dupuytren's contracture. Urology 2004, 64:399-404

75. Satish L, Laframboise WA, O'Gorman DB: Identification of differentially expressed genes in fibroblasts derived from patients with Dupuytren's contracture. BMC Med Genomics 2008, 1:1-10.

76. Ulrich D, Ulrich F, Piatkowski A, Pallua N: Expression of matrix metalloproteinases and their inhibitors in cords and nodules of patients with Dupuytren's disease. Arch Orthop Trauma Surg 2009, 129:1453-1459.

77. Bayat A, Winder C, Stanley J, Day P, Goodacre R: Proteome analysis of dupuytren's disease differentiating between disease tissue phenotypes (nodule, cord and transverse palmar fascia) and control palmar fascia. J Hand Surg 2006, 31:5.

78. O'Gorman D, Howard JC, Varallo VM, Cadieux P, Bowley E, McLean K, Pak BJ, Gan BS: Identification of protein biomarkers in Dupuytren's contracture using surface enhanced laser desorption ionization time-of-flight mass spectrometry (SELDI-TOF-MS). Clin Invest Med 2006, 29:136-145.

79. Kraljevic Pavelic S, Sedic M, Hock K, Vucinic S, Jurisic D, Gehrig P, Scott M, Schlapbach R, Cacev T, Kapitanovic S, Pavelic K: An integrated proteomics approach for studying the molecular pathogenesis of Dupuytren's disease. J Pathol 2009, 217:524-533.

80. Rhodes DR, Tomlins SA, Varambally S, Mahavisno V, Barrette T, KalyanaSundaram S, Ghosh D, Pandey A, Chinnaiyan AM: Probabilistic model of the human protein-protein interaction network. Nat Biotechnol 2005, 23:951-959

81. von Mering $C$, Jensen $\sqcup$, Kuhn M, Chaffron S, Doerks T, Krüger B, Snel B, Bork $P$ : STRING 7 - recent developments in the integration and prediction of protein interactions. Nucleic Acids 2007, 35:D358-D362.

82. ter Kuile BH, Westerhoff HV: Transcriptome meets metabolome: hierarchical and metabolic regulation of the glycolytic pathway. FEBS Lett 2001, 500:169-171.

83. Lazebnik Y: Can a biologist fix a radio? Or, what I learned while studying apoptosis. Cancer Cell 2002, 2:179-182.

84. Emery AE: The muscular dystrophies. The Lancet 2002, 359:687-695.

85. Williams R, Mamotte C, Burnett J: Phenylketonuria: an inborn error of 1413 phenylalanine metabolism. Clin Biochem Rev 2008, 29:31-41.

86. Weigelt B, Reis-Filho JS: Histological and molecular types of breast cancer: is there a unifying taxonomy? Nat Rev Clin Oncol 2009, 6:718-730.

87. Westerhoff HV, Kolodkin A, Conradie R, Wilkinson SJ, Bruggeman FJ, Krab K, van Schuppen JH, Hardin H, Bakker BM, Moné MJ, Rybakova KN, Eijken M, van Leeuwen HJ, Snoep JL: Systems biology towards life in silico: mathematics of the control of living cells. J Math Bio/ 2009, 58:7-34.

88. Au-Yong ITH, Wildin CJ, Dias JJ, Page RE: A review of common practice in Dupuytren surgery. Tech Hand Up Extrem Surg 2005, 9:178-187.

89. Badalamente MA, Hurst LC, Hentz VR: Collagen as a clinical target: nonoperative treatment of Dupuytren's disease. J Hand Surg 2002, 27:788-798.

90. Gilpin D, Coleman S, Hall S, Houston A, Karrasch J, Jones N: Injectable collagenase Clostridium histolyticum: a new nonsurgical treatment for Dupuytren's disease. J Hand Surg Am 2010, 35:2027-2038.

91. Snoep JL, Bruggeman F, Olivier BG, Westerhoff HV: Towards building the silicon cell: a modular approach. Biosystems 2006, 83:207-216.

92. Hucka M, Finney A, Sauro HM, Bolouri H, Doyle JC, Kitano H, Arkin AP, Bornstein BJ, Bray D, Cornish-Bowden A, Cuellar AA, Dronov S, Gilles ED, Ginkel M, Gor V, Goryanin II, Hedley WJ, Hodgman TC, Hofmeyr JH, Hunter PJ, Juty NS, Kasberger JL, Kremling A, Kummer U, Le Novère N, Loew LM, Lucio D, Mendes P, Minch E, Mjolsness ED, et al.: The systems biology markup language (SBML): a medium for representation and exchange of biochemical network models. Bioinformatics 2003, 19:524-531.

93. Cuellar AA, Lloyd CM, Nielsen PF, Bullivant DP, Nickerson DP, Hunter PJ: An overview of CellML 1.1, a biological model description language. Simulation 2003, 79:740-747.

94. Jeong E, Nagasaki M, Saito A, Miyano S: Cell system ontology: representation for modeling, visualizing, and simulating biological pathways. In Silico Biol 2007, 7:623-638

95. Demir E, Cary MP, Paley S, Fukuda K, Lemer C, Vastrik I, Wu G, D'Eustachio P, Schaefer C, Luciano J, Schacherer F, Martinez-Flores I, Hu Z, Jimenez-Jacinto V, Joshi-Tope G, Kandasamy K, Lopez-Fuentes AC, Mi H, Pichler E, Rodchenkov I, Splendiani A, Tkachev S, Zucker J, Gopinath G, Rajasimha H, Ramakrishnan R, Shah I, Syed M, Anwar N, Babur O, et al.: The BioPAX community standard for pathway data sharing. Nat Biotechnol 2010, 28:935-942.

96. Le Novère N, Hucka M, Mi H, Moodie S, Schreiber F, Sorokin A, Demir E, Wegner K, Aladjem MI, Wimalaratne SM, Bergman FT, Gauges R, Ghazal P Kawaji H, Li L, Matsuoka Y, Villéger A, Boyd SE, Calzone L, Courtot M, Dogrusoz U, Freeman TC, Funahashi A, Ghosh S, Jouraku A, Kim S, Kolpakov F, Luna A Sahle S, Schmidt E, et al:: The Systems Biology Graphical Notation. Nat Biotechnol 2009, 27:735-741.

97. Hoops S, Sahle S, Gauges R, Lee C, Pahle J, Simus N, Singhal M, Xu L, Mendes P, Kummer U: COPASI - a COmplex PAthway SImulator. Bioinformatics 2006, 22:3067-3074

98. Shannon P, Markiel A, Ozier O, Baliga NS, Wang JT, Ramage D, Amin N, Schwikowski B, Ideker T: Cytoscape: a software environment for integrated models of biomolecular interaction networks. Genome Res 2003, 13:2498-2504

99. Calvano SE, Xiao W, Richards DR, Felciano RM, Baker HV, Cho RJ, Chen RO, Brownstein BH, Cobb JP, Tschoeke SK, Miller-Graziano C, Moldawer LL, Mindrinos MN, Davis RW, Tompkins RG, Lowry SF; Inflamm and Host Response to Injury Large Scale Collab. Res. Program: A network-based analysis of systemic inflammation in humans. Nature 2005, 437:1032-1037.

100. Olivier BG, Snoep JL: Web-based kinetic modelling using JWS Online. Bioinformatics 2004, 20:2143-2144.

101. Le Novère $N$, Bornstein B, Broicher A, Courtot M, Donizelli M, Dharuri H, Li L, Sauro H, Schilstra M, Shapiro B, Snoep JL, Hucka M: BioModels Database: a free, centralized database of curated, published, quantitative kinetic models of biochemical and cellular systems. Nucleic Acids Res 2005, 34:D689-D691

102. Le Novère N, Finney A, Hucka M, Bhalla US, Campagne F, Collado-Vides J, Crampin EJ, Halstead M, Klipp E, Mendes P, Nielsen P, Sauro H, Shapiro B, Snoep $J$, Spence HD, Wanner BL: Minimum information requested in the annotation of biochemical models (MIRIAM). Nat Biotechnol 2005, 23:1509-1515

103. Humphries M, Reynolds A: Cell-to-cell contact and extracellular matrix. Curr Opin Cell Biol 2009, 21:613-615.

104. van der Greef J, Hankemeier T, McBurney RN: Metabolomics-based systems biology and personalized medicine: moving towards $n=1$ clinical trials? Pharmacogenomics 2006, 7:1087-1094. 
105. Kim YS, Maruvada P, Milner JA: Metabolomics in biomarker discovery: future uses for cancer prevention. Future Oncol 2008, 4:93-102.

106. Hollywood K, Brison DR, Goodacre R: Metabolomics: current technologies and future trends. Proteomics 2006, 6:4716-4723. doi:10.1186/ar3438

Cite this article as: Rehman S, et al.: Dupuytren's: a systems biology disease.

Arthritis Research \& Therapy 2011, 13:238. 